\title{
The role of IL-10 in Mycobacterium avium subsp. paratuberculosis infection
}

\author{
Tariq Hussain ${ }^{1}$, Syed Zahid Ali Shah", Deming Zhao ${ }^{1}$, Srinand Sreevatsan ${ }^{2}$ and Xiangmei Zhou ${ }^{{ }^{*}}$ (D)
}

\begin{abstract}
Mycobacterium avium subsp. paratuberculosis (MAP) is an intracellular pathogen and is the causative agent of Johne's disease of domestic and wild ruminants. Johne's disease is characterized by chronic granulomatous enteritis leading to substantial economic losses to the livestock sector across the world. MAP persistently survives in phagocytic cells, most commonly in macrophages by disrupting its early antibacterial activity. MAP triggers several signaling pathways after attachment to pathogen recognition receptors (PRRs) of phagocytic cells. MAP adopts a survival strategy to escape the host defence mechanisms via the activation of mitogen-activated protein kinase (MAPK) pathway. The signaling mechanism initiated through toll like receptor 2 (TLR2) activates MAPK-p38 results in up-regulation of interleukin-10 (IL-10), and subsequent repression of inflammatory cytokines. The anti-inflammatory response of IL-10 is mediated through membrane-bound IL-10 receptors, leading to trans-phosphorylation and activation of Janus Kinase (JAK) family receptor-associated tyrosine kinases (TyKs), that promotes the activation of latent transcription factors, signal transducer and activators of transcription 3 (STAT3). IL-10 is an important inhibitory cytokine playing its role in blocking phagosome maturation and apoptosis. In the current review, we describe the importance of IL-10 in early phases of the MAP infection and regulatory mechanisms of the IL-10 dependent pathways in paratuberculosis. We also highlight the strategies to target IL-10, MAPK and STAT3 in other infections caused by intracellular pathogens.
\end{abstract}

Keywords: Mycobacterium avium subsp. paratuberculosis (MAP), Mitogen-activated protein kinase (MAPK), Toll like receptor 2 (TLR2), Interleukin-10 (IL-10), Janus Kinase (JAK), Signal transducer and activators of transcription-3 (STAT3)

\section{Background}

Mycobacterium avium subsp. paratuberculosis (MAP) is the causative agent of paratuberculosis or Johne's disease (JD), chronic progressive granulomatous enteritis in ruminants. This disease was first described by Dr. Heinrich Albert Johne and Dr. Herman Markus in 1895, during examination of a cow's intestine with a history of reduced milk production and progressive emaciation [1].

The pathogenesis of paratuberculosis is divided into three distinct phases: Silent infection phase, with the appearance of no clinical signs, but animals intermittently shed MAP in the faeces, Subclinical phase: there is an altered immune response with no weight loss or

\footnotetext{
* Correspondence: zhouxm@cau.edu.cn

${ }^{1}$ National Animal Transmissible Spongiform Encephalopathy Laboratory and key Laboratory of Animal and Zoonosis of Ministry Agriculture, College of Veterinary Medicine and State key Laboratory of Agrobiotechnology, China Agricultural University, Beijing 100193, People's Republic of China Full list of author information is available at the end of the article
}

diarrhoea [2], while clinical disease phase: characterized by profuse diarrhoea, marked weight loss, that can be diagnosed by routine MAP detecting procedures [3]. In the clinical phase majority of the animals die due to severe dehydration and emaciation [1, 4]. Apart from common domesticated animals such as cattle, sheep and goats MAP also infect a wide range of other wild ruminants such as deer $[5,6]$. The most common route of infection is fecal-oral for all age of animals, while calves can also get the infection via contaminated milk. MAP is also detected in the saliva of cows, indicating that saliva might be a potential mode of transmission [7-9]. Serious economic losses from paratuberculosis occurs due to early culling of the animals with decreased milk production on one hand, but on the other hand loss of capital investments in treating secondary infections, such as mastitis and reduced fertility [10]. Paratuberculosis is also considered a potential zoonotic threat. In 1913, 
Dalziel reported the link between MAP and human Morbus Crohn disease (CD). Several studies have demonstrated the presence of MAP in CD cases, but the causative role of MAP in CD is not established yet $[11,12]$. Similarly McNees and colleagues reported that MAP can be cultured from mononuclear cells of Crohn's disease patient's but it does not establish the etiology [13].

Immunological responses observed in paratuberculosis begin with a robust T-helper1 (Th1) type response predominantly enhanced interferon-gamma (IFN- $\gamma$ ) production $[14,15]$. The hallmark of paratuberculosis is shift in immune response from a cell mediated Th1-type response to a humoral $\mathrm{T}$ helper2 (Th2) type response with the progression of disease from a subclinical to clinical phase [16]. Similarly, in ovine model of paratuberculosis, it is observed that the cellular immune response attenuates in natural and experimental MAP infected animals in more advanced phase of disease [17]. MAP rapidly (within 6-24 h) shutdown the pro-inflammatory $\mathrm{T}$ cell immune response by promoting immunosuppressive cytokines (IL-10, TGF- $\beta$ ) in in-vitro models . Impairment of CD40 signaling, which is an important macrophage receptor for CD40L on Th1 cells to maintain a Th1 immune response [18]. Mononuclear phagocytic cells (Macrophages), serves as intracellular niche for the MAP survival and multiplication. Macrophages have several pathogen recognition receptors (PRRs), involved in the uptake of mycobacteria $[19,20]$. Toll like receptors are family of cell membrane receptors that initiate cell signaling associated with mycobacterium infection [21]. Several studies indicated that pathogenic mycobacteria signal through TLR2 to suppress macrophage antimicrobial responses and antigen presentations $[22,23]$. MAP initiates signaling via binding with TLR2 of bovine mononuclear phagocytic cells that result in the activation of MAPK-p38 with a high level of IL-10 production and low level of IL-12 [24-27]. Pathogenic mycobcteria contains mannosylated lipoarabinomannan (Man-LAM) while arabinosylated lipoarabinomannan (Ara-LAM) is usually found in the cell wall of non-pathogenic mycobacteria. Man-LAM is one of the important pathogen associated molecular pattern (PAMP) of MAP that ligate with TLR2 to enhance IL-10 production as well as transient expression of tumor necrosis factor alpha (TNF- $\alpha$ ) [26]. Furthermore, it is reported that antigen recognition via TLR2/4 and CD14 in in-vitro and in-vivo lead to oversecretion of IL-10 by disrupting inflammatory responses and generation of adoptive immunity, thereby providing a niche for the persistent survival of pathogen [28].

IL-10 is a potent anti-inflammatory cytokine, crucial for down-regulating pro-inflammatory genes, induced by TLR signaling [29]. IL-10 is not only an essential immunoregulator in host immunity, but it also accounts for the intracellular survival of mycobacterium due to its inhibitory activity against anti-mycobacterial functions of macrophages [30]. The absence of IL-10 leads to better clearance of some pathogens with no enhanced immuno-pathology [31, 32]. The level of IL-10 production depends on the type and strength of the stimulus, while the molecular mechanisms for the regulation of IL-10 differ according to cell type, although some common mechanisms also exist [33]. The main signaling pathways for the production and regulation of IL-10 in phagocytic cells are mitogen-activated protein kinases (MAPKs) pathways, nuclear factor kappa-B (NF-kB) and signal transducer and activators of transcription-3 (STAT3). IL-10 is known to suppress macrophage activation and down-regulate anti-inflammatory and antimicrobial responses such as the production of nitric oxide (NO2), TNF- $\alpha$, and IL-12 [34, 35]. IL-10 promotes the viability of host cells by inhibiting autophagy, via activating B-cell lypmphoma2 (Bcl2) [36]. Feng and colleagues reported that transgenic mice expressing human IL-10 under the control of major histocompatibility complex class II promoter (hu10Tg) were more susceptible to MAP infection than the wild-type mice. In addition, hu10Tg mice strongly inhibited anti-mycobacterial response of the macrophages such as apoptosis, production of TNF, nitric oxide, and IL-12p40 [37].

Successful phagolysosomal maturation is an important innate immune response for the clearance of intracellular pathogens. MAPK-p38 plays an important role in the signaling cascades during mycobacterial infection [38-40] and is associated with arresting phagosome-lysosome fusion and maturation [41]. MAP interference with phagosome maturation in the infected macrophages depends on the MAPK-p38 signaling pathway activated by Man-LAM and also plays a role in the survival of Mycobacterium avium subsp avium (MAA) [26]. Interestingly, it was observed that Man-LAM but not Ara-LAM induce IL-10 secretion in LPS stimulating DCs [42]. IL-10 also mediates its anti-inflammatory effects on macrophages by signaling through STAT3 [43, 44]. STAT3 plays an important role as a signaling mediator of IL-6 and IL-10 family members and other cytokines [45]. The blocking of IL-10 in Mycobacterium tuberculosis (Mtb) infected macrophages, allows phagosome maturation, but the addition of IL-10 to cells infected with killed Mtb successfully inhibits its maturation, resulting in enhanced survival of Mtb via inhibiting phagosome maturation by IL-10 [46]. Moreover, it is reported that IL-10 secreting transgenic mice were unable to clear the infection and developed bacterial burden after being challenged with BCG (Mycobacterium bovis), suggesting that IL-10 help in mycobacterial infection [47]. On the other hand the blocking of IL-10 in Mtb susceptible $\mathrm{CBA} / \mathrm{J}$ mice minimized the pulmonary bacterial load and improved the animal survival during chronic infection [48]. In MAP infection it has been investigated that the 
over expression of IL-10 dependent MAPK-p38 [24] is associated with the survival of macrophages by inhibiting the apoptosis phenomenon [35]. IL-10 negatively regulate apoptosis via the activation of STAT3 to promote the transcription of anti-apoptotic and cell cycle progression genes such as BCLXL, CyclinD1, CyclinD2, CyclinD3, and CyclinA, Pim1, c-Myc and p19 (INK4D) [49].

It is clear from previous studies that IL-10 regulation can be a potential hotspot for devising therapeutic measures in intracellular pathogens including MAP. IL-10 regulation can be exploited through recently developed microRNAs (miRNAs) controlling strategies. Several microRNAs regulate the expression of IL-10 by targeting its transcription at 3UTR or by targeting pathways that regulate IL-10 production. Apart from miRNAs, several compounds such as ammonium trichloro (dioxoethylene-O, O') tellurate (AS101), SD169 and an antihelminth niclosamide can be used to inhibit IL-10 mediated anti-inflammatory activity that has already shown promising results in various infections.

\section{The role of IL-10 in paratuberculosis}

The role of IL-10 is well established in paratuberculosis, as IL-10 plays an important role in the cross talk between innate and adoptive immune responses of the host. IL-10 mediated suppression of IFN- $\gamma$ secretion in peripheral blood of cattle and goats exposed to MAP infection is also documented [50, 51]. MAP stimulates IL10 secretion from ovine and bovine monocytes derived antigen presenting cells [52-54]. Coussens and colleagues investigated the expression of cytokine genes in Peripheral blood mononuclear cells (PBMC) of subclinical paratuberculosed and disease-free animals, an increase of IFN- $\gamma$ gene expression was observed in subclinical animals, while in-vitro stimulation did not show any increase in the expression of IFN- $\gamma$. In contrast, IL-10 gene expression was low in unstimulated cells from both groups, but MAP stimulated cells showed an enhanced expression of IL-10 in subclinically infected animals in comparison of number of cytokines, including IFN- $\gamma$, TGF- $\beta$, TNF- $\alpha$, IL- $1 \alpha$, IL-4, IL-6, IL-8, and IL-12p35 [55]. Janagama and colleagues investigated that bovine monocyte derived macrophages (BMDM) stimulated with bovine MAP isolate (MAP1018) upregulated IL-10 at the transcript level and downregulated TNF- $\alpha$ at both protein and transcript levels in BMDM cells compared with human and sheep MAP (MAP S7565) isolates [56]. Man-LAM of MAP has been identified as one of the ligands that modulates macrophage function and induce a rapid and prolonged expression of IL-10 as well as transient expression of TNF- $\alpha$ [26]. Khalifeh and Stabel also found that IL-10 secretion was elevated upon incubation of live MAP with PBMC from naturally infected cattle, when compared to healthy animals [38]. In ovine paratuberculosis, animals with paucibacillary (type of lesions largely composed of lymphocytes with some macrophages and giant cells and few acid-fast bacteria) disease are more likely to have elevated levels of IFN- $\gamma$ in illeal tissue while elevated levels of IL-10 are more likely in multibacillary (type of lesions contain few lymphocytes and numerous clusters of macrophages having acid-fast bacteria) animals [57]. Narnaware and colleagues also reported that MAP baison strain upregulate both TGF- $\beta$ and IL-10 genes in paucibacillary and multibacillary cases in bullocks while a higher magnitude of antiinflammatory cytokines were observed in animals of multibacillary lesions [58].

IL-10 is an important immunoregulator on one hand, but on the other hand it inhibits anti-mycobacterial activity of macrophages and promotes the intracellular survival of mycobacteria [30]. Previously it was reported that Map41, one of important recombinant protein of MAP that elicited IFN- $\gamma$ production in PBMC from cattle infected with MAP [59]. In the study of Reiko and colleagues it was observed that there is an increased production of IL-10 in response to Map41 from experimentally infected calves as early as $2-4$ weeks than that of IFN- $\gamma$. This characteristic expression of IL-10 in MAPinfected cattle seems to be playing important role in the pathogenesis of paratuberculosis, and could be an important diagnostic indicator [30]. Further studies revealed that the blood cells from calves immunized with MAP produced higher amounts of IL-10 against Map41 stimulation than those calves immunized with various mycobacterium species, in addition, experimentally infected guinea pigs with 14 various mycobacterium species showed high specificity of IL-10 production to MAP after stimulation of splenocytes by Map41 recombinant protein [30]. John et al., [27] also showed that specific MAP recombinant proteins induced an elevated expression of IL-10 by macrophages whereas other proteins are involved in survival of mycobacteria within the macrophages as well as activating the MAPKp38 pathway [27]. M. avium 101 infected C57BLJ6 mice produced peak IL-10 after 2 weeks of infection and remained high throughout the period of infection. Further investigations on the role of IL-10 in the survival of M. avium 101 , mice were infected and simultaneously treated with anti-IL-10 antibodies resulted in 2 to 3 log unit less bacterial load in the spleen and liver than the control mice [60]. Another study reported that $\mathrm{BALB} / \mathrm{c}$ mice were more susceptible to $M$. avium infection while the reduction of IL-10 activity in these animals through anti-IL10R mAb, or by using IL-10 knockout mice reduced the susceptibility to $M$. avium infection. Moreover, the inhibition of IL-10 also increased the efficacy of antimycobacterial therapy in infected BALB/c mice [61]. 
Similarly, when the level of IL-10 was increased by using recombinant IL-10 or IL-10 transgenic mice, animals were more prone to disease $[62,63]$. These findings regarding the over production of IL-10 in MAP infected animals as well as MAP or Map recombinant proteins stimulating macrophages suggest the importance of IL10 in the progression of paratuberculosis.

\section{The role of IL-10 mediated inhibition of proinflammatory cytokines in paratuberculosis}

During mycobacterial infections, cytokine networks triggered by macrophages generally determine the outcome of an infection [64]. IL-10 also inhibits the antimicrobial activity of macrophages by down regulating the expression of IL-12 and TNF- $\alpha$ [34, 65]. Previous studies shown that IL-10 act as a possible mediator of immunosuppressants associated with MAP infection [35, 52]. Investigations on bovine monocytes treated with anti-IL10 antibodies before challenge with MAP showed an over expression of IL-12, TNF- $\alpha$ and also promoted the bactericidal activity of these cells [65]. Earlier studies reported that IFN- $\gamma$ and TNF- $\alpha$ plays a key role in the control of intracellular Mtb $[64,66]$. IL-12 is one of the important pro-inflammatory cytokine produced primarily by antigen-presenting cells (APCs), including monocytes/macrophages and dendritic cells [67]. IL-12 is composed of p35 (encoded by Il12a) and p40 (encoded by $I l 12 b$ ) chains, and it principally activates natural killer (NK) cells and induce the differentiation of naive CD4+ $\mathrm{T}$ lymphocytes to become IFN- $\gamma$ producing Th1 effecter cells [67]. IFN- $\gamma$, acts on APCs to augment IL-12 secretion in a positive feedback loop $[68,69]$. On the other hand, the most important and well studied negative regulator of TLR-induced IL-12 production is IL-10 [70]. IL-10 suppresses the production of IL-12 at transcriptional level by down regulating both $I L 12 a$ and $I l 12 b$ genes [71]. IL-10 overexpressed transgenic mice challenged with Mtb via respiratory route shown a highly significant increase in bacterial number in the lungs, while decreased mRNA production of TNF- $\alpha$ and IL$12 \mathrm{p} 40$, and a marked decrease in the secretion of Agspecific IFN- $\gamma$ was observed [72].

IL-10 is induced in many situations together with proinflammatory cytokines, although the pathways that induce IL-10 expression more likely negatively regulate the expression of these pro-inflammatory cytokines [33]. Dendritic cells (DC) and macrophages produce TNF- $\alpha$ as a primary response of infection and tissue damage, plays an important role in activation and recruitment of leukocytes [73], and has been demonstrated to be involved in the host defence against Mtb [74]. IL-10 requires Stat3, Jak1, and two distinct regions of the IL-10 receptor intracellular domain to inhibit TNF- $\alpha$ production in lipopolysaccharide stimulated macrophages.
Macrophages deficient in Stat3 or Jak1 are unable to inhibit lipopolysaccharide induced TNF- $\alpha$ production following treatment with murine IL-10 [75]. IFN- $\gamma$ is a key molecule that helps in the activation of macrophages with the production of reactive oxygen and nitrogen species, activation of $\mathrm{T}$ cells and maturation of DCs [76]. IFN- $\gamma$ is the early marker of cell-mediated immune response and essential for effective clearance of the mycobacteria, but with the progression of disease, an immunosuppressive cytokine IL-10 becomes predominant $[50,51]$. An enhanced host generated IFN- $\gamma$ and IL-17A were observed in $\mathrm{CBA} / \mathrm{J}$ mice during $\mathrm{BCG}$ vaccination resulted in additional protection against Mtb by inhibition of IL-10 activity through anti-IL-10R mAb treatment [77]. In the clinical stages of paratuberculosis, it was observed that IL-10 suppressed the production of IFN- $\gamma$ [38]. Neutralization of IL-10 in vitro resulted in increased IL12 , TNF- $\alpha$, and IFN- $\gamma$ mRNA expression by bovine monocytes exposed to MAP or purified protein derivative (Johnin) [50]. Mice deficient in IL-10 eliminated M.bovis BCG faster than wild-type mice, while macrophages in the granulomas expressed high level of MHC class II molecule, TNF- $\alpha$, acid phosphatase and inducible nitric oxide sythase (iNOS) [78]. The serine/threonine protein kinase $\mathrm{C}$ (PKC) theta plays an important role in host defence against Salmonella typhimurium, as resulted in high number of bacteria in spleen and liver of PKC theta-/- mice. Furthermore PKC theta-deficient macrophage expressed significantly higher levels of IL-10 in in-vivo and in-vitro when challenged with S.typhimurium or LPS/IFN- $\gamma$ while neutralization of IL-10 improved the control of S.typhimurium infection in PKC theta deficient macrophages [79]. It has been shown that the exogenous treatment of IL-10 inhibit macrophage function like the release of NO and TNF- $\alpha$, IL-6, and GM-CSF secretion, induced by LPS [80]. Taken together IL-10 enhances the growth and persistent survival of MAP in phagocytic cells by inhibiting the secretion of pro-inflammatory cytokines.

\section{The role of IL-10 in the shift of immune responses from Th1 to Th2 dominated immune responses in paratuberculosis infection}

The progression of paratuberculosis from subclinical to clinical form is mainly dependent on a gradual shift in immune response from a cell-mediated Th1 type response to a humoral Th2 response [16]. The naive helper $\mathrm{T}$ cells mainly differentiate into either Th1 cells or Th2 cells effecter cells after activation. The Th1 cells secrete IFN- $\gamma$ and TNF- $\alpha$ and activate macrophages to kill microbes located within the phagosomes. On the other hand Th2 cells secrete interleukins 4, 5, 10, and 13 (IL-4, IL-5, IL-10, and IL-13) and will mainly defend the animal against extracellular pathogens (Fig. 1). Initially, Th2 cells were the main populations of $\mathrm{T}$ cells that 


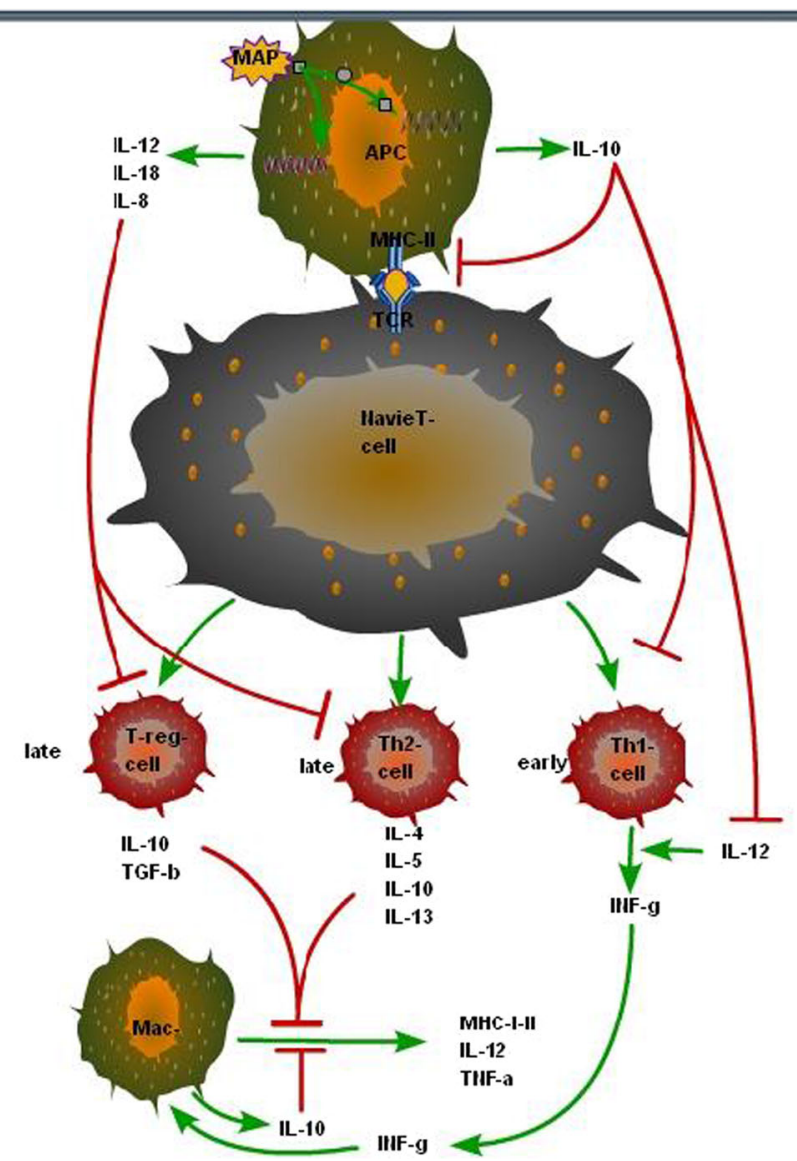

Fig. 1 A classical switch between Th-1/Th-2 immune response in paratuberculosis: Navi Th cell differentiate into subpopulation of effectors Th cells when bind to antigen presented by antigen presenting cell (APC). In MAP infection the early differentiated effectors T helper1 (Th1) cell promote protective cell mediate immune response. Th1 cell secrets cytokines such as interferon-gamma (INF- $\gamma$ ) and Interleukin-12(IL-12) and promote the activation of macrophages. In the later stages of infection T helper 2 (Th2) and regulatory T cell are dominant. Th2 and T-reg cell secret anti-inflammatory cytokines such as IL-4, IL-5, IL-10, IL-13 and TGF- $\beta$. These anti-inflammatory cytokines block the activation of macrophages and also down-regulate the cytokines secreted by Th1 cell and prevent cell mediated immune response while promote humoral response mediated by Th2 cell

produce IL-10 in a sustained manner $[81,82]$. One theory suggests that the differentiation of naive $\mathrm{T}$ cell into subpopulation of Th1/Th2 cells based on the host immune response mediated by polarization of APCs (Fig. 1) after initial contact with an antigen [83]. The early stage of paratuberculosis is controlled by a cell-mediated Th1 response activated by infected macrophages that express IFN- $\gamma$, IL-12 and TNF- $\alpha$ [84]. IFN- $\gamma$ and TNF- $\alpha$ are important cytokines of the Th1 response, enhancing bactericidal activity of macrophages with the production of reactive oxygen and nitrogen species, activation of $\mathrm{T}$ cells and maturation of DCs [76, 85]. Another important role for IFN- $\gamma$ is the induction of IL-12 which further directs CD4 cells to the Th1 subset. Studies have demonstrated that CD4 cells are also the primary source of IFN- $\gamma$ in MAP infection [86]. In response to mycobacterial infection, different cytokines like IL-12, IL-17 and
IL-23 contribute in the development of Th1 cells [87]. During MAP infection, Th1-type response usually occurs early in the infection cycle with an increase production of IFN- $\gamma$ [88]. De Silva and colleagues reported that IL10 mediated Th2 response becomes dominant when the disease is in progress, with a decline in Th1 response. Similarly Begg and colleagues reported that during clinical stage of the disease Th2 type immune responses are more dominant than Th1 type. Further studies suggest that there is a classical switch between Th-1/Th-2 immune response in ruminants infected with MAP [17]. During Mtb infection various type of $\mathrm{T}$ helper cells (such as Th1, Th2, Th17, and regulatory $\mathrm{T}$ cells) are present but Th1 type of cells are more commonly involved in impaired growth and dispersion of Mtb [89]. In sheep MAP infection, paucibacillary lesions have been correlated with a stronger cell-mediated Th1 response 
than those with multibacillary lesions with a high level of IL-10 expression [88, 90]. A similar trend of higher levels of Th2 type cytokines IL-4, IL-10, IL-2 were observed in cattle with multibacillary lesions [91]. Recent studies also demonstrated that high expressions of IL-10 and TGF- $\beta$ in the advanced stage of MAP infection with a diffuse granulomatous lesions, suggest the predominance of Th2 response, which shows a switch of Th1 to Th2 response. In addition, an increased expression of IL-10 and TGF- $\beta$ could have limited Th1 cytokines and cellular infiltration resulting in less tissue pathology but persistence of MAP infection in bullocks [58].

The role of IL-10 predicted with the cytokine signaling model is similar to the cell model where IL-10 can enhance the Th2 response and suppress the Th1 response which promotes the progression of disease [92]. IL-10 is implicated at many levels of tuberculosis disease, such as directing Th2-type cell expansion in the lung [92, 93]. Several studies shown that some molecular mechanisms exist that cause a switch from IFN- $\gamma$ production to IL-10 by Th1 cells. It is predicted that IL-4 favor the expression of IL-10, also reported by Gesham et al. [92] that IL-4 inhibit Th1 (IFN- $\gamma$ ) response. In Mtb, IL-10 also block the migration of $\mathrm{T}$ cell to the site of infection most commonly impairing the recruitment of Th1 cells to the lungs of infected mice [94]. Hence the control of Mtb is negatively regulated by IL-10 and inhibit the progression of early innate to late adoptive Th1 response [94]. Similarly, another intracellular pathogen Ehrlichia muris induced early IL-10 production which impaired bacterial clearance in wild-type mice and deteriorate IFN- $\gamma$ production while in IL-10 deficient mice IFN- $\gamma$ production by $\mathrm{CD} 4 \mathrm{~T}$ cell was restored and induced a protective immune response [95]. The lack of IL-10 production by $\mathrm{T}$ cells resulted in an increased ability of mice to control intracellular Brucella abortus infection and elevated the production of pro-inflammatory cytokines. Moreover it is suggested that early IL-10 production by CD $25+C D 4+$ $T$ cells modulates macrophage activation that is beneficial for bacterial survival and persistent infection [96]. In the clinical form of paratuberculosis, it is observed that Th2 type response dominate with an increased level of cytokines such as IL-4, IL-5 and IL-10 [84, 97]. The dynamics of IL-10, TGF- $\beta$ and IFN- $\gamma$ gene expression in the ileum, ileocecal junction, ileocecal lymph node, and mesenteric lymph nodes of healthy cows as well as those in subclinical and clinical stages of infection. IL-10 and TGF- $\beta$ mRNA levels were significantly higher in all tissues of cows with clinical disease. In contrast, IFN- $\gamma$ gene expression was significantly higher only in animals with subclinical infection [52]. These reports suggest that IL-10 production during paratuberculosis gradually shift protective Th1 cell mediated immune response to humoral response mediated by Th2 cells.

\section{The role of IL-10 mediated inhibition of phagosome maturation in paratuberculosis}

Phagocytosis is an essential process by which macrophages engulf invading pathogens, apoptotic cells and other foreign particles. Phagocytosis triggers the activation of multiple transmembrane signaling pathways that lead to the formation of a sealed intracellular compartment called phagosome [98]. Pathogenic species of mycobacteria have evolved mechanisms that enhance their survival ability within macrophages by inhibiting acidification and maturation of phagosomal compartment which is necessary for the progression of a phagosome into a functional phagolysosome [99, 100]. MAP adopts multiple strategies for their intracellular survival; one of them involves the inhibition of phagosomal acidification and maturation. MAP blocks the phagosome maturation into phagolysosome by interfering the localization of lysosomal markers and prevents the $\mathrm{pH}$ to go below 6.3 in J774 macrophages [101]. Previous studies reported that MAP enhances the phosphorylation of MAPK-p38 in bovine monocytes, resulted in the inhibition of phagosomal acidification and killing of MAP to over-express IL-10 [24]. While the inhibition of p38 phosphorylation by the application of pharmacologically active substances enhance the bactericidal activity of bovine monocytes against MAP organism and increase the acidification of phagosome [21, 24, 35]. IL10 negatively regulates the maturation of phagosome in Mtb [46]. Man-LAM from MAP interacts with PRRs of macrophages promote IL-10 production and further inhibit phagosomal acidification [26]. Other studies showed that monocytes treated with p38 inhibitor before challenging with MAP and Mtb promote phagosomal maturation and also inhibit IL-10 production $[41,46]$. In addition, macrophages treated with cytokines lead to an increase in the acidification and maturation of phagosomal compartments containing MAP [102]. Furthermore, phagosome maturation was enhanced by blocking STAT3 activity in Mtb-infected macrophages [46]. The acidification of phagosomal compartment in macrophages infected by pathogenic mycobacteria is inhibited through the elimination of phagosomal proton pump, the Vacuolar Hp ATPase (V-ATPase), from their phagosomal membranes [103]. Phagosomal body having MAP or Mtb are deficient in V-ATPase [99]. It is clear from the above findings that $\mathrm{p} 38$ phoshorylation promote IL-10 production and further increase MAP resistance to defence mechanisms of the host by blocking the acidification and maturation of phagosomal compartments.

\section{Role of IL-10 mediated apoptosis in paratuberculosis}

The process of programme cell death (apoptosis) is also an essential mechanism of the host for the control of 
intracellular infections [103]. However, some pathogens may prevent host cell apoptosis, circumventing efferocytosis, and ensuring limited immune system detection [104]. MAP keeps the host cell alive by preventing apoptotic suicide of macrophages. Macrophages infected with mycobacteria tend to activate apoptotic pathways, resulting in cell death [105]. However, pathogenic strains of mycobacteria induce less apoptosis as compared to low pathogenic strains. For example, bovine monocyte-derived macrophages (BMDM) have a greater percentage of apoptotic cells when incubated with the less pathogenic organism MAA in comparison to bovine pathogen MAP [106]. Pathogenic mycobacteria also limit apoptosis by inhibiting TNF- $\alpha$ expression and releasing soluble TNF-receptor-2 (TNFR2) that neutralize TNF- $\alpha$ activity [105]. This is accomplished primarily through over expression of IL-10 [35, 107]. IL-10 not only suppresses TNF- $\alpha$ synthesis but also enhance soluble TNFR2 [105]. High concentration of IL-10 also impairs apoptosis induced by Mtb in alveolar macrophages [108]. IL-10 significantly upregulates the expression of suppressor of cytokine signaling-3 (SOCS3), and modulates oxidized lowdensity lipoprotein (oxLDL) to inhibit apoptosis in endothelial cells [109]. It has been reported that IL-10 inhibits the production of inflammatory cytokines by macrophages and protect cell from apoptosis [110]. In addition, IL-10 induces its anti-apoptotic properties via overexpression of SOCS3 that inhibit inflammatory cytokine involved in the progression of apoptosis. This phenomenon was also reported in a recent study showing that SOCS3 and SOCS1 suppressed cytokineinduced apoptosis [111]. IL-10 also prevents apoptotic cell death of infected macrophages by inhibiting multiple components that positively regulate apoptosis phenomena and promote the survival of MAP.

\section{IL-10 regulating signaling pathways}

Phagocytic cells have various pathogen recognition receptors (PRRs) for initiating signaling cascades. Among different PRRs TLRs are important pattern recognition receptors of phagocytic cells, signaling pathways followed by TLR 2 and TLR4 are potent inducers of IL-10 [112]. It has been suggested that TLR2 agonists are specialized in inducing IL-10 expression by APCs [112, 113]. Several studies indicate that pathogenic mycobacteria signal through TLR2 is crucial for the induction of IL-10, suppress macrophage antimicrobial responses and antigen presentation [114]. TLR2/4 is major signaling receptors of phagocytic cells activate MAPK pathway and may activate the NF-kB pathway after ligation with Man-LAM and $19 \mathrm{kDa}$ of MAP [25]. The common signaling pathways that induce the regulation of IL-10 in phagocytic cells are MAPK, NF-kB, and STAT $[25,43]$.

\section{MAPK pathway}

Mitogen-activated protein kinase (MAPK) is a signal transduction pathway belongs to a large family of serine/ threonine kinases, which constitute major inflammatory signaling pathways from the cell surface to the nucleus [115]. There are three well-characterized subfamilies of MAPKs: the extracellular signal-regulated kinases (ERK), the c-Jun NH2-terminal kinases (JNK), and the p38 family of kinases (p38 MAPKs) [116, 117]. Both ERK and p38 are crucial for the Mtb-induced production of TNF$\alpha$, while p38 is more essential for the secretion of IL-10 in macrophage [40]. MAP induced IL-10 expression by bovine monocytes is mediated through activation of MAPK-p38, but not MAPK-ERK, or MAPK-JNK [24, 41, 105]. Blocking the MAPK-p38 pathway inhibits the capacity of MAP to induce IL-10 expression, suppress IL12, block phagosome acidification, and inhibit organism killing [41]. MAPK-p38 kinase exists as four isoforms, alpha, beta, gamma and delta [118]. In case of p38 alpha, it is the sites Thr180/Tyr182 that become dual phosphorylated, signaling activation within the cell. Following TLR ligation, signaling cascades are activated through Toll/IL-1 receptor (TIR)-domain-containing adaptor molecules, such as myeloid differentiation primary response protein 88 (MYD88) which consists of a Cterminal TIR and an $\mathrm{N}$-terminal death domain (DD). The later interacts with the DD of a serin/threonin protein kinase, IL-1 receptor-associated kinases (IRAK). Binding to MyD88 enables IRAK4 to phosphorylate the subsequently recruited IRAK1, thereby inducing the activation of its kinase activity. Autophosphorylated IRAK1 subsequently dissociates from the receptor complex and associates with TIR-domain containing adaptor protein inducing IFN- $\beta 6$ (TRAF6) [119]. The IRAK1-TRAF6 complex interacts at the plasma membrane with another preformed complex consisting of TGF- $\beta$-activated protein kinase 1 (TAK1) TAK binding protein1 (TAB1) and TAB2 or TAB3. This interaction induces phosphorylation of TAB2/TAB3 and TAK1, leading to their translocation to the cytoplasm together with TRAF6 and TAK1, whereas IRAK1 is degraded at the plasma membrane. In the cytoplasm, TAK1 is then activated, resulting in the activation of the MAPK-p38, ERK and JNK. TAK1 activation also, resulting in the activation of IKKs (IkB kinases), which then phosphorylate the IkBs (inhibitor of NF-kB). This phosphorylation allows ubiquitylation and subsequent degradation of $\mathrm{I} \kappa \mathrm{B}$, thereby releasing NF- $\mathrm{kB}$. NF- $\mathrm{kB}$ is consequently free to translocate into the nucleus and induce the expression of its target genes [120]. These down-signaling cascade leading to activation and nuclear translocation of transcription factors such as specific protein 1(Sp1) [121], activator protein (AP), CCAAT/enhancer binding protein(C/EBP) $\beta$ and $\delta$ [122], c-musculoaponeurotic fibrosarcoma factor 
(c-Maf) [123], nuclear factor $\mathrm{k}-\mathrm{B}$ (NFkB) [124], and phosphorylated cyclic AMP element binding protein (CREB) [125] playing critical role in the expression of IL-10. Although, MAPK-p38 pathway is an antimicrobial suppressive response within macrophages, as a result the activation of this pathway could enable intracellular survival of MAP and also induce the production of the anti-inflammatory cytokine such as IL-10 [41, 69].

\section{NF-kB pathway}

Several studies suggested that NF- $\kappa B$ plays a role in regulating IL-10 production. There are five rel proteins in NF-kB: RelA (p65), RelB and cRel (which contain transactivation domains) and $\mathrm{p} 50$ and $\mathrm{p} 52$ (which are expressed as the precursor proteins p105 (NF-kB1) and p100 (NF-kB2)\} [126]. Gene knockout studies have also shown that NF-kB proteins may have both pro and antiinflammatory roles. Homodimers of the p50 subunit of NF-kB, which lack transactivation domains, have been shown to repress expression of NF-kB target genes and inhibit inflammation [127]. Further studies have shown that administration of IL-10 fusion protein inhibited IL$12 \mathrm{p} 40$ production dependent on $\mathrm{p} 50 / \mathrm{p} 105$ expression in macrophages [128]. These studies suggest that NF-kB may have anti-inflammatory roles by directly inhibiting the expression of pro-inflammatory genes and by manipulating the expression or activity of anti-inflammatory cytokines such as IL-10 [127]. The transcription of IL-10 is also promoted by one of NF-kB family member that is NF-kB1 (p50), where p50 can homodimerize and form a complex with the transcriptional co-activator CREBbinding protein to activate transcription, while other Rel family members appear to play a negligible role in IL-10 transcription [129]. NF-kB1-deficient macrophages have lower levels of IL-10 expression than control cells following TLR activation [112].

\section{STAT pathway}

Signal transducer and activators of transcription (STATs) are a family of transcription factors that play crucial roles in regulating a number of diverse biological functions including cell proliferation, differentiation, apoptosis, inflammatory response, immunity, and angiogenesis [130]. There are seven STAT proteins (STATs 1, 2, 3, 4, 5a, 5b, and 6), which are activated by the signals from cytokine and growth factor receptors in the plasma membrane and regulate gene transcription [131]. A unique feature of STAT proteins includes signal transduction through the cytoplasm and functioning as transcription factors in the nucleus [132]. STAT proteins are activated by phosphorylation of specific tyrosine residues, following which they form stable homodimers or heterodimers with other STAT proteins through reciprocal phosphotyrosine-SRC homology 2 (SH2) domain interactions [133]. STAT dimers then translocate to nucleus where they regulate the transcription of a set of specific genes. STAT3 is unique of all STAT family protein, play important role as a signaling mediator of IL- 6 and IL-10 family members and other cytokines such as leptin and G-CSF [133]. IL-10 also induces IL-10 in monocyte-derived macrophages in an autocrine manner via activation of STAT3 factor [45]. IL10 bind to IL-10R1/IL-10R2 receptor complex that will lead the phosphorylation of cytoplasmic protein Janus kinase (JAK) 1 (associated with the IL-10 receptor $\alpha$ chain) and phosphorylation of tyrosine kinase (Tyk) 2 (associated with the IL-10 receptor $\beta$ chain) leads to the phosphorylation and activation of transcription factor, STAT3 [43), resulting in up-regulation of IL-10 responsive genes, such as SOCS3, and downregulation of a number of LPSinducible genes including pro-inflammatory cytokines in peripheral blood mononuclear cells [134]. STAT3 is critical regulator of IL-10 and have been proposed to transactivate $I L 10$ gene in macrophage and T cell lines of mouse or human origin [135]. IL-10 mediates its antiinflammatory effects on macrophages by signaling through STAT3 $[43,45]$. STAT3 has been reported to directly activate transcription of IL-10 and TGF- $\beta$ genes [136]. Moreover, STAT3 has been shown to compete for binding of NF-kB Rel to the IL-12p35 promoter inhibiting its transcription [137]. Genetic and biochemical evidence from both human and mouse systems indicate that STAT3 is required to generate IL-10-induced anti-inflammatory responses [43].

\section{The role of miRNA in regulation of IL-10 and other signalling pathways in immune cells in paratuberculosis infection}

The best possible therapeutic strategy towards achieving the goal of targeting MAPK pathway by itself or its downstream signaling in paratuberculosis can be through the regulation of IL-10 directly or via STAT3 pathway. The miRNAs are small, non-coding RNAs molecules that bind complementary sequences in the 3 untranslated regions (UTRs) of the target genes [138]. In the immune system miRNAs play an important role in the development and differentiation of hematopoietic subset of cells like, DC development [139]. Recent studies found that miRNAs have critical role in both innate and adoptive immune response [140], such as macrophage polarization, $\mathrm{T}$ cell and $\mathrm{B}$ cell differentiation [141]. The role of miRNAs has been investigated in the regulation of IL-10 and its related pathways in immune modulating cells [142, 143]. Feng et al., [144] demonstrated that miR-466 1 up-regulate IL-10 expression in TLRtriggered macrophages both at mRNA and protein levels. Some miRNAs are IL-10-dependent such as miR187, playing a role in IL-10 mediated suppression of TNF- $\alpha$, IL- 6 , and the p40 subunit of IL-12 (IL-12p40) 
produced by primary human monocytes following activation of TLR4 [145]. On the other hand several studies investigated that miRNAs also negatively regulate the expression of IL-10 and can be used to neutralize the anti-inflammatory effect of IL-10 in different immune suppressive diseases. In addition to miR-155, miR-147 also counter regulates IL-10 subsequently promoting pro-inflammatory functions in TLR-triggered macrophages [146]. The overexpression of miR-98 inhibited TLR4-triggered IL-10 production and promoted COX-2 expression, by targeting the 3'untranslated region of IL10 transcripts [147]. Similarly, exogenously mimic miR27 a negatively regulates the expression of $\mathrm{IL}-10$ in macrophages stimulated by LPS, while promote proinflammatory cytokines [148]. MiR-689, miR-124, and miR-155 were the most strongly associated miRNAs predicted to mediate pro-inflammatory pathways and activation of M1 phenotype of macrophage [149]. In terms of both phenotype and function, macrophages display two well established polarized phenotypes are referred to as the classically activated macrophages (M1) and the alternatively activated macrophages (M2) [150]. M1 phenotype produce large amounts of pro-inflammatory cytokines, express high levels of major histocompatibility complex molecules and are potent killers of pathogens and tumour cells [151], while M2 phenotype, usually activated by the IL-4/IL-13 immune complex, IL-10, or TGF- $\beta$, are associated with an immunosuppressive phenotype, an enhanced release of anti-inflammatory cytokines [142]. As reported by Ouiment and colleagues that, miR-33 promote M1 phenotype by up-regulating the expression of M1 markers such as Il6, Nos2, and $I l 1 b$, while reduced the expression of the M2 macrophages markers, Mrc1 (mannose receptor CD206) and Fizz1/Retnla [152]. Sisi et al., [143] reported that miR23a and 27a inhibit the polerization of M2 phenotype while promote M1 phenotype by targeting 3UTR of JAK1/STAT6 and IRF4/PPAR- $\gamma$. The cluster of miR-23a/ 27a/24-2 enhance the production of inflammatory mediators (IL-1b, IL-6, IL-12 and TNF-a) while inhibit antiinflammatory cytokine such as IL-10 [144]. In addition to that other studies reported that miRNAs, such as miR-155, miR-146a and miR-9 negatively regulated the activation of MAPK-p38 and JNK signaling pathways [153]. The activation of JAK-STAT3 pathway playing important role in the regulation of IL-10 and also inhibit anti-bactericidal activities of phagocytic cells. Recently it has been determined that miRNAs also have role in the regulation of STAT3 expression, such as 23a/27a/24-2 got therapeutic significance by inhibiting JAK1-Stat3 and synergistically promote apoptosis [154]. Recently it is demonstrated that overexpression of miR-124, miR-519a and miR-351 inhibit STAT3 by targeting 3 untranslated region of STAT3 $[154,155]$. The miR-
204 also inhibits the activation of STAT3 and BCL2 by targeting JAK2 [156].

Apart from miRNAs there are some other compounds that have role in the regulation of IL-10 or IL-10 dependent pathways in several diseases, such as ammonium trichloro (dioxoethylene-O, O') tellurate (AS101) inhibit IL-10 production by dephosphorylation of Stat3, followed by reduced expression of $\mathrm{Bcl}-2$ [157]. In addition AS101 deactivate Akt that leads to a decrease in pGSK3 expression and reduce IL-10 production [158]. Sinuani and colleagues reported that AS101 also negatively regulate TGF- $\beta$ in uninephrectomized rats [159]. AS101 also got immunemodulatory properties by inhibiting anti-inflammatory cytokines, IL-10 while promote pro-inflammatory cytokines [160]. On the other hand, Myers et al., found that SD-169, a novel oral inhibitor of MAPK-p38 [161]. Another important compound that inhibits the activation of MAPK/ERK1/2 and ІкB kinases is niclosamide, an FDA-approved anti-helminthic compound, also down-regulate Stat 3 and Bcl-2 family members such as Mcl-1 [162]. You et al., [163] also investigated the role of niclosamide in the progression of lung cancer by blocking STAT3/Bcl2/Bcl-Xl signaling pathway. These compounds can be used to control the progression of paratuberculosis by targeting IL-10 regulating pathways in mononuclear phagocytic cells.

\section{Conclusions}

Mycobacterium avium subspecies paratuberculosis (MAP) is the causative agent of paratuberculosis. MAP not only lead to high economic losses in livestock sector but also a potential zoonotic threat by considering a contributing factor in Crohn's disease of humans. The hallmark of MAP reactivation is the failure of the host immune response to restrain the bacterial growth. The most critical immune evasion mechanism of MAP survival in macrophages is the activation of MAPK-p38 dependent TLR2MyD88 adopter protein. MAPK-p38 activation inhibits antimicrobicidal activity of macrophages and over expression of IL-10. It is understood that IL-10 plays a critical role in maintaining homeostasis in the body by resolving inflammation during acute infection or any injury, while high level of IL-10 in paratuberculosis promote the survival of MAP. The excessive amount of IL-10 reduces the bactericidal ability of defense cells. IL-10 is used as a weapon by the bacilli to interfere with proper macrophage activation during active infections. The pathways involved in the upregulation of IL-10 such as MAPK can be vital for developing a therapeutic strategy for the control of paratuberculosis. Recent studies highlighted the role of miRNAs in pathogen-host interactions. It has been investigated that certain miRNAs positively regulates the host immune response against Mtb. Similarly, different miRNAs regulates various signaling components of MAPKp- 
38 pathway as well as anti-inflammatory cytokines. Recent studies on profiling of miRNAs during clinical and subclinical infection of MAP gave a new perspective to MAP control via miRNA techniques. These studies shown that circulating miRNAs in MAP infected animals retain their integrity under longterm suboptimal storage temperatures and are considered as potential biomarkers $[164,165]$ that can be exploited for devising the future paratuberculosis control strategies. Apart from miRNAs several compounds such as AS101, SD169 and niclosamide can be used to target IL-10 mediated anti-inflammatory activity. The knowledge reviewed about the mechanism of MAP pathogenesis will likely lead to a better understanding of paratuberculosis treatment and control.

\section{Abbreviations}

TGF- $\beta$ : Transforming growth factor-beta; TRAF6: TIR-domain containing adaptor protein inducing IFNB 6; AP: Activator protein; APCs: Antigenpresenting cells; AS101: Ammonium trichloro (dioxoethylene-O, O') tellurate; Bcl2: B-cell lypmphoma2; BMDM: Bovine monocyte-derived macrophages; CD: Morbus crohn disease; CREB: Cyclic AMP element binding protein DD: Death domain; ERK: Extracellular signal-regulated kinases; IFNY: Interferon-gamma; IL-10: Interleukin-10; IL-12: Interleukin-12; IRAK: IL-1 receptor-associated kinases; IKBs: Inhibitor of NF-KB; JAK: Janus Kinase; JNK: CJun NH2-terminal kinases; LPS: Lypopolysaccharide; MAA: Mycobacterium avium subsp avium; Man-LAM: Mannosylated lipoarabinomannan; MAP: Mycobacterium avium subsp. Paratuberculosis; MAPK: Mitogen-activated protein kinase pathway; MDM: Monocytes derived macrophages; miRNAs: Micro-RNAs; Mtb: Mycobacterium tuberculosis; MYD88: Myeloid differentiation primary response protein 88; NF-kB: Neuclear factor kappa-B; NK cells: Natural killer cells; NO2: Nitic oxide; oxLDL: oxidized low-density lipoprotein; PAMP: Pathogen associated molecular pattern; PBMC: Peripheral blood mononuclear cells; PRRs: Pathogen recognition receptors; SOCS3: Suppressor of cytokine signaling-3; Sp1: Specific protein 1; STAT3: Signal transducers and activators of transcription 3; TAB1: TAK binding protein 1; TAK1: TGF $\beta$-activated protein kinase 1; Th1: T-helper1; Th2: T helper2; TIR: Toll/IL-1 receptor; TLR2: Toll like resceptor; TNF-a: Tumor necrosis factor alpha; Tyk: Tyrosine kinase 2; UTRs: Untranslated regions

\section{Acknowledgment}

The authors declare no financial, personal, or professional conflict of interest. All authors have critically read and approved this work. We would also like to thank Prof. Paul Barrow for his useful comments before final submission of the manuscript.

\section{Funding}

This work was supported by the MOST-RCUK international cooperation project (Project No. 2013DFG32500), National Natural Science Foundation of China (Project No.31572487). 2016 CAU Foreign Experts Major Projects (Project No: 2012z018). High-end Foreign Experts Recruitment Program (Project No: GDW20151100036).

\section{Availability of data and materials}

Not applicable.

\section{Authors' contributions}

TH wrote the review manuscript, SZAS helped in figures compilation, DZ give the useful idea behind the manuscript compilation and XZ and SS reviewed the article before final submission. All authors read and approved the manuscript.

\section{Competing interests}

The authors declare that they have no competing interests.

\section{Consent for publication}

All authors have critically read and approved this work.

\section{Ethics approval and consent to participate}

According to the journal's requirement we hereby declare that it is a review article where no animal or human experiments were conducted, we followed the strict ethical rules according to compilation of already published data on the current topic.

\section{Author details}

${ }^{1}$ National Animal Transmissible Spongiform Encephalopathy Laboratory and key Laboratory of Animal and Zoonosis of Ministry Agriculture, College of Veterinary Medicine and State key Laboratory of Agrobiotechnology, China Agricultural University, Beijing 100193, People's Republic of China. ${ }^{2}$ Veterinary Population Medicine Department, College of Veterinary Medicine, University of Minnesota, St Paul, MN, USA.

Received: 17 September 2016 Accepted: 22 November 2016 Published online: 01 December 2016

\section{References}

1. Manning EJ, Collins MT. Mycobacterium avium subsp. paratuberculosis: pathogen, pathogenesis and diagnosis. Rev Sci Tech. 2001;20:133-50.

2. Buergelt CD, Hall C, McEntee K, Duncan JR. Pathological evaluation of paratuberculosis in naturally infected cattle. Vet Pathol. 1978:15:196-207.

3. Whitlock RH, Buergelt C. Preclinical and clinical manifestations of paratuberculosis (including pathology). Vet Clin North Am Food Anim Pract. 1996;12:345-56

4. Chiodini RJ, Van Kruiningen HJ, Merkal RS. Ruminant paratuberculosis (Johne's disease): the current status and future prospects. Cornell Vet. 1984;74:218-62.

5. Buergelt CD, Ginn PE. The histopathologic diagnosis of subclinical Johne's disease in North American bison (Bison bison). Vet Microbiol. 2000:77:325-31.

6. Yadav D, Singh SV, Singh AV, Sevilla I, Juste RA, Singh PK, Sohal JS. Pathogenic 'Bison-type' Mycobacterium avium subspecies paratuberculosis genotype characterized riverine buffalo (Bubalus bubalis) in North India. Comp Immunol Microbiol Infect Dis. 2008:31:373-87.

7. Abbas M, Munir M, Khalig SA, Hag MI, Tanveer Khan M, Qureshi ZU. Detection of paratuberculosis in breeding bulls at Pakistani semen production units: a continuous source of threat. IRSN Vet Sci. 2011;10:1-4.

8. Sorge SS, Kurnick S, Streevatsan S. Detection of Myocbacterium avium subspecies paratuberculosis in the saliva of dairy cows: a pilot study. Vet Microbiol. 2013;164:383-6.

9. Stevenson K. Genetic diversity of Mycobacterium avium subspecies paratuberculosis and the influence ofstrain type on infection and pathogenesis: a review. Vet Res. 2015;46(64):1-13.

10. Lombard JE. Epidemiology and economics of paratuberculosis. Vet Clin North Am Food Anim Pract. 2011;27:525-35.

11. Chiodini RJ, Chamberlin WM, Sarosiek J, McCallum RW. Crohn's disease and the mycobacterioses: a quarter century later. Causation or simple association? Crit Rev Microbiol. 2012;38:52-93.

12. Liverani E, Eleonora S, Carla C, Paola DM, Andrea B. Review, Mycobacterium avium subspecies paratuberculosis in the etiology of Crohn's disease, cause or epiphenomenon. World J Gastroenterol. 2014;20(36):13060-70.

13. McNees AL, Markesich D, Zayyani NR, Graham DY. Mycobacterium paratuberculosis as a cause of Crohn's disease. Expert Rev Gastroenterol Hepatol. 2015;9(12):1523-34.

14. Gwozdz JM, Thompson KG, Murray A, Reichel MP, Manktelow BW, West DM. Comparison of three serological tests and an interferon-gamma assay for the diagnosis of paratuberculosis in experimentally infected sheep. Aust Vet J. 2000;78:779-83.

15. Stabel JR, Whitlock RH. An evaluation of a modified interferongamma assay for the detection of paratuberculosis in dairy herds. Vet Immunol Immunopathol. 2001;79:69-81.

16. Leite FL, Livia BE, Bruce P, John PB, Timothy AR, Judith RS. ZAP-70, CTLA-4 and proximal $T$ cell receptor signaling in cows infected with Mycobacterium avium subsp. paratuberculosis. Vet Immunol Immunopathol. 2015;167:15-21.

17. Begg DJ, de Silva K, Carter N, Plain KM, Purdie A, Whittington RJ. Does a Th1 over Th2 dominancy really exist in the early stages of Mycobacterium avium subspecies paratuberculosis infections? Immunobiology. 2011;216(7):840-6.

18. Sommer S, Pudrith CB, Colvin CJ, Coussens PM. Mycobacterium avium subspecies paratuberculosis suppresses expression of IL-12p40 and iNOS 
genes induced by signalling through CD40 in bovine monocytederived macrophages. Vet Immunol Immunopathol. 2009;128:44-52.

19. Stokes RW, Thorson LM, Speert DP. Nonopsonic and opsonic association of Mycobacterium tuberculosis with resident alveolar macrophages is inefficient. J Immunol. 1998;160:5514-21.

20. Astarie-Dequeker C, N'Diaye EN, Le Cabec V, Rittig MG, Prandi J, Maridonneau-Parini I. The mannose receptor mediates uptake of pathogenic and nonpathogenic mycobacteria and bypasses bactericidal responses in human macrophages. Infect Immun. 1999;67:469-77.

21. Fratti RA, Chua J, Deretic V. Induction of p38 mitogen-activated protein kinase reduces early endosome autoantigen 1(EEA1) recruitment to phagosomal membranes. J Biol Chem. 2003;278:46961-7.

22. Noss EH, Pai RK, Sellati TJ, Radolf JD, Belisle J, Golenbock DT, Boom WH, Harding CV. Toll-like receptor 2-dependent inhibition of macrophage class II $\mathrm{MHC}$ expression and antigen processing by $19-\mathrm{kDa}$ lipoprotein of Mycobacterium tuberculosis. J Immunol. 2001;167:910-8.

23. Banaiee N, Kincaid EZ, Buchwald U, Jacobs Jr WR, Ernst JD. Potent inhibition of macrophage responses to IFN- by live virulent Mycobacterium tuberculosis is independent of mature mycobacterial lipoproteins but dependent on TLR2. J Immunol. 2006;176:3019-27.

24. Souza CD, Evanson OA, Weiss D. Mitogen activated protein kinasep38 pathway is an important component of the anti-inflammatory response in Mycobacterium avium subsp. Paratuberculosis infected bovine monocytes. Microb Pathog. 2006;41:59-66.

25. Weiss DJ, Souza CD, Evanson OA, Sanders M, Rutherford M. Bovine monocyte TLR2 receptors differentially regulate the intracellular fate of Mycobacterium avium subsp. paratuberculosis and Mycobacterium avium subsp. avium. J Leukoc Biol. 2008:83:48-55.

26. Souza C, Davis WC, Eckstein TM, Sreevatsan S, Weiss DJ. Mannosylated lipoarabinomannans from Mycobacterium avium subsp. paratuberculosis alters the inflammatory response by bovine macrophages and suppresses killing of Mycobacterium avium subsp. avium organisms. PLoS One. 2013;8(9):1-6.

27. John PB, Judith RS, Elizabeth L, Maria Clara DC, Souza CD. Mycobacterium avium Subspecies paratuberculosis Recombinant Proteins Modulate Antimycobacterial Functions of Bovine Macrophages. PLoS ONE. 2015;10(6):1-14

28. Cyktor JC, Turner J. Interleukin-10 and Immunity against Prokaryotic and Eukaryotic Intracellular Pathogens. Infect Immun. 2011;79(8):2964-73.

29. Claire EM, Frederick JS, Joseph EQ, Sarah LD, Susan RQ, Murray PJ, Luke AJ, O'Neill. IL-10 inhibits miR-155 induction by Toll-like receptors. J Biol Chem. 2010;285(27):20492-8.

30. Nagata R, Satoko K, Yuu M, Xuebo W, Tadashi Y, Yasuyuki M. A specific induction of interleukin-10 by the Map41 recombinant PPE antigen of Mycobacterium avium subsp. Paratuberculosis. J Vet Immunol Immunopathol. 2010;135:71-8.

31. Ejrnaes M, Christophe MF, Marianne MM, Eleanor ML, Lisa MT, Shane C, Matthias GH. Resolution of a chronic viral infection after interleukin-10 receptor blockade. J Exp Med. 2006;203:2461-72

32. Brooks DG, Trifilo MJ, Edelmann KH, Teyton L, McGavern DB, Oldstone MB. Interleukin-10 determines viral clearance or persistence in vivo. Nat Med. 2006;12:1301-9.

33. Margarida $S$, Anne $O^{\prime} G$. The regulation of $\mathrm{IL}-10$ production by immune cells. Nat Rev Immunol. 2010;10:170-81.

34. Kaufmann SH. Protection against tuberculosis: cytokines, T cells, and macrophages. Ann Rheum Dis. 2002:61:54-8.

35. Weiss DJ, Evanson OA, Souza CD. Increased expression of interleukin-10 and suppressor of cytokine signaling-3 associated with susceptibility to Johne's disease. Am J Vet Res. 2005;66:1114-20.

36. Verma SK, Krishnamurthy P, Girikipathi VN, Abramova T, Gumpert A, Khan M, Emily N, Johnson J, Benedict C, Koch W, Kishore R. Ang II-induced Pathological Autophagy is inhibited by IL-10 via Akt Dependent Inhibition of Beclin 1 in Mice Heart. J Cell Biol Funct. 2015;132:A14287.

37. Feng CG, Kullberg MC, Jankovic D, Cheever AW, Caspar P, Coffman RL, Sher AA. Transgenic Mice Expressing Human Interleukin-10 in the AntigenPresenting Cell Compartment Show Increased Susceptibility to Infection with Mycobacterium avium Associated with Decreased Macrophage Effector Function and Apoptosis. Infect Immun. 2002;70(12):6672-9.

38. Khalifeh MS, Stabel JR. Effects of gamma interferon, interleukin-10, and transforming growth factor beta on the survival of Mycobacterium avium subsp. paratuberculosis in monocyte-derived macrophages from naturally infected cattle. Infect Immun. 2004;72:1974-82.
39. Reiling N, Blumenthal A, Flad HD, Ernst M, Ehlers S. Mycobacteriainduced TNF-alpha and IL-10 formation by human macrophages is differentially regulated at the level of mitogen-activated protein kinase activity. J Immunol. 2001;167:3339-45.

40. Song CH, Lee JS, Lee SH, Lim K, Kim HJ, Park JK, Paik TH, Jo EK. Role of mitogen-activated protein kinase pathways in the production of tumor necrosis factor-alpha, interleukin-10, and monocyte chemotactic protein-1 by Mycobacterium tuberculosis H37Rv-infected human monocytes. J Clin Immunol. 2003;23:194-201.

41. Souza CD, Evanson OA, Weiss DJ. Regulation by Jun N-terminal kinase/ stress activated protein kinase of cytokine expression in Mycobacterium avium subsp. paratuberculosis-infected bovine monocytes. Am J Vet Res. 2006:67:1760-5.

42. Geijtenbeek TBH, Vliet SJ, Koppel EA, Hernandez MS, Christine MJE, Vandenbroucke-Grauls CM, Ben A, Yvette van K. Mycobacteria Target DC-SIGN to Suppress Dendritic Cell Function. J Exp Med. 2003:197(1):7-17.

43. Williams L, Bradley L, Smith A, Foxwell B. Signal transducer and activator of transcription 3 is the dominant mediator of the anti-inflammatory effects of IL-10 in human macrophages. J Immunol. 2004;172:567-76.

44. Murray PJ. The JAK-STAT signaling pathway: input and output integration. J Immunol. 2007;178:2623-9.

45. Kuchipudi SV. Review Article the Complex Role of STAT3 in Viral Infections. J Immunol Res. 2015;10:1-9.

46. Leary SO, O'Sullivan MP, Joseph K. IL-10 Blocks Phagosome Maturation in Mycobacterium tuberculosis-Infected Human Macrophages. Am J Respir Cell Mol Biol. 2011:45:172-80.

47. Murray PJ, Wang L, Onufryk C, Tepper RI, Young RA. T cell-derived IL-10 antagonizes macrophage function in mycobacterial infection. J Immunol. 1997:158(1):315-21.

48. Beamer GL, Flaherty DK, Assogba BD, Stromberg P, Gonzalez-Juarrero M Malefyt RW, Vesosky B, Turner J. Interleukin-10 Promotes Mycobacterium tuberculosis Disease Progression in CBA/J Mice. J Immunol. 2008;181(8): 5545-50.

49. Donnelly RP, Dickensheets H, Finbloom DS. The interleukin-10 signal transduction pathway and regulation of gene expression in mononuclear phagocytes. J Interferon Cytokine Res. 1999;19:563-73.

50. Buza JJ, Hikono H, Mori Y, Nagata R, Hirayama S, Aodon-geril, Bari AM, Shu Y, Tsuji NM, Momotani E. Neutralization of interleukin-10 significantly enhances gamma interferon expression in peripheral blood by stimulation with Johnin purified protein derivative and by infection with Mycobacterium avium subsp. paratuberculosis in experimentally infected cattle with paratuberculosis. Infect Immun. 2004:72:2425-8.

51. Lybeck KR, Storset AK, Olsen I. Neutralisation of interleukin-10 from CD14+ monocytes enhances gamma interferon production in peripheral blood mononuclear cells from Mycobacterium avium subsp. paratuberculosis infected goats. Clin Vaccine Immunol. 2009:16:1003-11.

52. Khalifeh MS, Stabel JR. Upregulation of transforming growth factor-beta and interleukin-10 in cows with clinical Johne's disease. Vet Immunol Immunopathol. 2004;99:39-46.

53. Berger ST, Griffin FT. A comparison of ovine monocyte-derived macrophage functions following infection with Mycobacterium avium ssp. avium and Mycobacterium avium ssp. paratuberculosis. Immunol Cell Biol. 2006:84:349-56.

54. Lei L, Hostetter JM. Limited phenotypic and functional maturation of bovine monocyte-derived dendritic cells following Mycobacterium avium subspecies paratuberculosis infection in vitro. Vet Immunol Immunopathol. 2007;120:177-86.

55. Coussens PM, Verman N, Coussens MA, Elftman MD, McNulty AM. Cytokine gene expression in peripheral blood mononuclear cells and tissues of cattle infected with Mycobacterium avium subsp. paratuberculosis: evidence for an inherent proinflammatory gene expression pattern. Infect Immun. 2004;72:1409-22.

56. Janagama HK, Kwang IJ, Vivek K, Paul C, Srinand S. Cytokine responses of bovine macrophages to diverse clinical Mycobacterium avium subspecies paratuberculosis strains.j. BMC Microbiol. 2006:6(10):1-12.

57. Smeed JA, Watkins CA, Rhind SM, Hopkins J. Differential cytokine gene expression profiles in the three pathological forms of sheep paratuberculosis. BMC Vet Res. 2007;3(18):1-11.

58. Narnaware SD, Periasamy S, Tripathi BN. Studies on pathology, cytokine gene expression and molecular typing of Mycobacterium avium subsp. 
paratuberculosis of naturally occurring Johne's disease in bullocks. Res Vet Sci. 2016;106:74-80.

59. Nagata R, Muneta Y, Yoshihara K, Yokomizo Y, Mori Y. Expression cloning of gamma interferon-inducing antigens of Mycobacterium avium subsp. paratuberculosis. Infect Immun. 2015;73:3778-82.

60. Bermudez L, Champs J. Infection with Mycobacterium avium Induces Production of Interleukin-10(IL-10), and Administration of Anti-IL-10 Antibody Is Associated with Enhanced Resistance to Infection in Mice. Infect Immun. 1993;61(7):3093-7.

61. Roque S, Nobrega C, Appelberg R, Neves MC. IL-10 Underlies Distinct Susceptibility of BALB/C and C57BL/6 Mice to Mycobacterium avium Infection and Influences Efficacy of Antibiotic Therapy. J Immunol. 2007;178:8028-35.

62. Jacobs M, Brown N, Allie N, Gulert R, Ryffel B. Increased resistance to mycobacterial infection in the absence of interleukin-10. Immunology. 2000;100:494-501

63. Murray PJ and Young RA. Increased antimicrobial immunity in interleukin10-deffecient mice. Infect Immun. 1999:67:3087-95.

64. Berrington WR, Hawn TR. Mycobacterium tuberculosis, macrophages, and the innate immune response: does common variation matter? Immunol Rev. 2007;219:167-86.

65. Weiss DJ, Evanson O, Souza CD. Critical role of interleukin-10 in the response of bovine macrophages to infection by Mycobacterium avium sub paratuberculosis. Am J Vet Res. 2005;66:21-726.

66. Raja A. Immunology of tuberculosis. Indian J Med Res. 2004;120:213-32.

67. Trinchieri G. Interleukin-12: a cytokine produced by antigen-presenting cells with immunoregulatory functions in the generation of T-helper cells type 1 and cytotoxic lymphocytes. Blood. 1994;84(12):4008-27.

68. Grohmann U, Belladonna ML, Vacca C, Bianchi R, Fallarino F, Orabona C, Fioretti MC, Puccetti P. Positive regulatory role of IL-12 in macrophages and modulation by IFN-gamma. J Immunol. 2001;167(1):221-7.

69. Ma X, Chow JM, Gri G, Carra G, Gerosa F, Wolf SF, Dzialo R, Trinchieri G. The interleukin 12 p40 gene promoter is primed by interferon gamma in monocytic cells. J Exp Med. 1996;183(1):147-57.

70. D'Andrea A, Aste-Amezaga M, Valiante NM, Ma X, Kubin M, Trinchieri G. Interleukin 10 (IL-10) inhibit human lymphocyte interferon gammaproduction by suppressing natural killer cell stimulatory factor/LL-12 synthesis in accessory cells. J Exp Med. 1993;178(3):1041-8.

71. Aste-Amezaga M, Ma X, Sartori A, Trinchieri G. Molecular mechanisms of the induction of IL-12 and its inhibition by IL-10. J Immunol. 1998;160(12):5936-44.

72. Turner J, Gonzalez-Juarrero M, Ellis DL, Basaraba RJ, Kipnis A, Orme IM, Cooper AM. In Vivo IL-10 Production Reactivates Chronic Pulmonary Tuberculosis in C57BL/6 Mice. J Immunol. 2002;169:6343-51.

73. Clark IA. How TNF was recognized as a key mechanism of disease. Cytokine Growth Factor Rev. 2007;18:335-43.

74. Keane J, Gershon S, Wise RP, Mirabile-Levens E, Kasznica J, Schwieterman WD, Siegel JN, Braun MM. Tuberculosis associated with infliximab, a tumor necrosis factor alpha-neutralizing agent. N Engl J Med. 2001;345:1098-104.

75. Joan KR, Takeda K, Akira S, Schreiber RD. Interleukin-10 Receptor Signaling through the JAK-STAT Pathway requirement for two distinct receptor-derived signals for anti-inflammatory action. J Biol Chem. 1999;274(23):16513-21.

76. Khalifeh MS, Al-Majali AM, Stabel JR. Role of nitric oxide production in dairy cows naturally infected with Mycobacterium avium subsp. paratuberculosis. Vet Immunol Immunopathol. 2009;131:97-104.

77. Pitt JM, Stavropoulos E, Redford PS, Beebe AM, Bancroft GJ, Young DB, O'Garra AA. Blockade of IL-10 Signaling during Bacillus Calmette-Guerin Vaccination Enhances and Sustains Th1, Th17, and Innate Lymphoid IFN-g and IL-17 Responses and Increases Protection to Mycobacterium tuberculosis Infection. J Immunol. 2012;189:4079-87.

78. Sullivan BM, Ousman J, Vanja L, Kristine V, Roderick B, Laurie HG and Igor K. Increased Susceptibility of Mice Lacking T-bet to Infection with Mycobacterium tuberculosis Correlates with Increased IL-10 and Decreased IFN- $\gamma$ Production. J Immunol. 2005;175:4593-602.

79. Obermair CP, Albrecht-Schgoer K, Peer S, Nairz M, Siegmund K, Klepsch V, Haschka D, Thuille N, Hermann-Kleiter N, Gruber T, Weiss G, Baier G. Role of PKCtheta in macrophage-mediated immune response to Salmonella typhimurium infection in mice. Cell Commun Signal. 2016;14(14):2-8.

80. Berlato C, Cassatella MA, Kinjyo I, Gatto L, Yoshimura A, Bazzoni F. Involvement of suppressor of cytokine signaling-3 as a mediator of the inhibitory effects of IL-10 on lipopolysaccharide-induced macrophage activation. J Immunol. 2002;168:6404-11.

81. Fiorentino DF, Bond MW, Mosmann TR. Two types of mouse T helper cell. IV. Th2 clones secrete a factor that inhibits cytokine production by Th1 clones. J Exp Med. 1989;170:2081-95.

82. Chang EY, Guo B, Doyle SE, Cheng G. Cutting edge: involvement of the type I IFN production and signaling pathway in lipopolysaccharide-induced IL-10 production. J Immunol. 2007;178:6705-9.

83. Stabel JR, Kimura K, Robbe-Austerman S. Augmentation of secreted and intracellular gamma interferon following johnin purified protein derivative sensitization of cows naturally infected with Mycobacterium avium subsp. paratuberculosis. J Vet Diagn Investig. 2007;19:43-51.

84. Stabel JR. Host responses to Mycobacterium avium subsp. paratuberculosis: a complex arsenal. Anim Health Res Rev. 2006;7:61-70

85. Lin PG, Flynn JL. Understanding latent tuberculosis: a moving target. Immunol. 2010;185(1):15-22.

86. Stabel JR, Robbe-Austerman S. Early immune markers associated with Mycobacterium avium subsp. paratuberculosis infection in a neonatal calf model. Clin Vaccine Immunol. 2011;18:393-405.

87. Khader SA, Bell GK, Pearl JE, Fountain JJ, Rangel-Moreno J, Cilley GE, Shen F, Eaton SM, Gaffen SL, Swain SL, Locksley RM, Haynes L, Randall TD, Cooper AM. IL-23 and IL- 17 in the establishment of protective pulmonary CD4+ T cell responses after vaccination and during Mycobacterium tuberculosis challenge. Nat Immunol. 2007;8(4):369-77.

88. de Silva K, Begg D, Carter N, Taylor D, Di Fiore L, Whittington R. The early lymphocyte proliferation response in sheep exposed to Mycobacterium avium subsp. paratuberculosis compared to infection status. Immunobiology. 2010;215(1):12-25.

89. O'Garra A, Redford PS, McNab FW, Bloom Cl, Wilkinson RJ, Berry MPR. The immune response in tuberculosis. Annu Rev Immunol. 2013:31:475-527.

90. de Silva K, Begg $D$, Whittington $R$. The interleukin 10 response in ovine Johne's disease. Vet Immunol Immunopathol. 2011:139(1):10-6.

91. Tanaka S, Sato M, Onitsuka T, Kamata H, Yokomizo Y. Inflammatory cytokine gene expression in different types of granulomatous lesions during asymptomatic stages of bovine paratuberculosis. Vet Pathol. 2005:42(5):579-88.

92. Gesham M, Eda S, Stabel J. Predicting the Role of IL-10 in the Regulation of the Adaptive Immune Responses in Mycobacterium avium Subsp. Paratuberculosis Infections Using Mathematical Models. PLoS ONE. 2015; 10(11):1-25.

93. Almeida AS, Lago PM, Boechat N, Huard RC, Lazzarini LC, Santos AR, Nociari M, Zhu H, Perez-Sweeney BM, Bang H, et al. Tuberculosis is associated with a down-modulatory lung immune response that impairs Th1-type immunity. J Immunol. 2009:183:718-31.

94. Redford PS, Murray PJ, O'Garra A. The role of IL-10 in immune regulationduring M. tuberculosis infection. Mucosal Immunol. 2011:4:261-70.

95. Singh AK, Thirumalapura NR. Early Induction of Interleukin-10 Limits Antigen-Specific CD4 T cell Expansion, Function, and Secondary Recall Responses during Persistent Phagosomal Infection. Infect Immun. 2014; 82(10):4092-103.

96. Xavier MN, Winter MG, Spees AM, Nguyen K, Atluri VL, Silva TMA, Baumler AJ, Muller W, Santos RL, Tsolis RM. CD4+ T Cell-derived IL-10 Promotes Brucella abortus Persistence via Modulation of Macrophage Function. PLoS Pathog. 2013:9(6):1-17.

97. Stabel JR. Transitions in immune responses to Mycobacterium paratuberculosis. Vet Microbiol. 2000;77:465-73.

98. Luzio JP, Pryor PR, Bright NA. Review, Lysosome fusion and Function. Nat Rev Mol Cell Biol. 2007:8:622-32.

99. Xu S, Cooper A, Sturgill-Koszycki S, Van Heyningen T, Chatterjee D, Orme I, Allen P, Russell D. Intracellular traficking in Mycobacterium tuberculosis and Mycobacterium aviuminfected macrophages. J Immunol. 1994;153:2568-78.

100. Ramachandra L, Noss E, Boom W, Harding C. Processing of Mycobacterium tuberculosis antigen 85B involves intraphagosomal formation of peptidemajor histocompatibility complex II complexes and is inhibited by live bacilli that decrease phagosome maturation. J Exp Med. 2001;194:1421-32.

101. Kuehnel MP, Goethe R, Habermann A, Mueller E, Rohde M, Griffiths G, Valentin-Weigand $\mathrm{P}$. Characterization of the intracellular survival of Mycobacterium avium ssp. paratuberculosis: phagosomal pH and fusogenicity in $\mathbf{J 7 7 4}$ macrophages compared with other mycobacteria. Cell Microbiol. 2001;3:551-66.

102. Schaible U, Sturgill-Koszychi S, Schlesinger P, Russell D. Cytokine activation leads to acidification and increases maturation of Mycobacterium avium- 
containing phagosomes in murine macrophages. J Immunol. 1998;160:1290-6.

103. Nelson N. The vacuolar Hp-APTase one of the most fundamental ion pumps in nature. J Exp Biol. 1992;172:19-27.

104. Sly LM, Hingley-Wilson SM, Reiner NE, McMaster WR. Survival of Mycobacterium tuberculosis in host macrophages involves resistance to apoptosis dependent upon induction of antiapoptotic Bcl-2 family member Mcl-1. J Immunol. 2003;170:430-7.

105. Pena AS, Karimi O, Crusius JB. A new avenue to investigate: the autophagic process. From Crohn's disease to Chlamydia. Drugs Today (Barc). 2009;45:113-7.

106. Koul A, Herget T, Klebl B, Ullrich A. Interplay between mycobacteria and host signaling pathways. Nat Rev. 2004;2:189-202.

107. Tessema MZ, Koets AP, Rutten VP, Gruys E. How does Mycobacterium avium subsp. paratuberculosis resist intracellular degradation? Vet Q. 2001;23:153-62.

108. Souza CD, Weiss DJ, Evanson OA. Role of the MAPK-ERK pathway in regulating cytokine expression by Mycobacterium avium subsp. paratuberculosis-infected bovine monocytes. Am J Vet Res. 2007;68(6):625-30.

109. Patel NR, Swan K, Li X, Tachado SD, Koziel H. Impaired M. tuberculosismediated apoptosis in alveolar macrophages from HIV1 persons: potential role of IL-10 and BCL-3. J Leukoc Biol. 2009;86:53-60.

110. Yin Y, Liu W, Ji G, Dai Y. The essential role of p38 MAPK in mediating the interplay of oxLDL and IL-10 in regulating endothelial cell apoptosis. Eur J Cell Biol. 2013;92:150-9.

111. Halvorsen $B$, Waehre $T$, Scholz $H$, Clausen $O P$, von der Thüsen JH, Müller FHH, Tonstad S, Hall C, Froland SS, Biessen EA, Damås JK, Aukrust P. Interleukin-10 enhances the oxidized LDL induced foam cell formation of macrophages by antiapoptotic mechanisms. J Lipid Res. 2005;46:211-9.

112. Madonna S, Scarponi C, Pallotta S, Cavani A, Albanesi C. Anti-apoptotic effects of suppressor of cytokine signaling 3 and 1 in psoriasis. Cell Death Dis. 2012;10(3):1-11.

113. Hu X, Paik PK, Chen J, Yarilina A, Kockeritz L, Lu TT, Woodgett JR, Ivashkiv LB. IFN- $\gamma$ suppresses IL-10 production and synergizes with TLR2 by regulating GSK3 and CREB/AP-1 proteins. Immunity. 2006;24:563-74.

114. Neta MG, Sutmuller R, Hermann C, Van der Graaf CA, Van der Meer JW, van Krieken JH, Hartung T, Adema G, Kullberg BJ. Toll like receptor-2 supress immunity against candida alibicans through induction of $\mathrm{I-10}$ and regulatory T cells. J Immunol. 2004;172:3712-8.

115. Lee JC, Laydon JT, McDonnell PC, Gallagher TF, Kumar S, Green D, McNulty $D$, Blumenthal MJ, Heys JR, Landvatter SW. A protein kinase involved in the regulation of inflammatory cytokine biosynthesis. Nature. 1994;372(6508): 739-46.

116. Hommes DW, Peppelenbosch MP, van Deventer SJH. Mitogen activated protein (MAP) kinase signal transduction pathways and novel antiinflammatory targets. Gut. 2002;52:144-51.

117. Johnson GL, Lapadat R. Mitogen-activated protein kinase pathways mediated by ERK, JNK, and p38 protein kinases. Science. 2002;298:1911-2.

118. Ashwell JD. The many paths to p38 mitogen-activated protein kinase activation in the immune system. Nat Rev Immunol. 2006:6:532-40.

119. Boonstra A, Rajsbaum R, Holman M, Marques R, Asselin-Paturel C, Pereira JP, Bates EE, Akira S, Vieira P, Liu YJ, Trinchieri G, O'Garra A. Macrophages and myeloid dendritic cells, but not plasmacytoid dendritic cells, produce IL-10 in response to MyD88- and TRIFdependent TLR signals, and TLRindependent signals. J Immunol. 2006;177:7551-8.

120. Doyle SL, O'Neill LA. Toll-like receptors: from the discovery of NFkappaB to new insights into transcriptional regulations in innate immunity. Biochem Pharmacol. 2006;72(9):1102-13.

121. Bright bill H, Plevy S, Modlin R, Smale S. A prominent role for Sp1 during lipopolysaccharide-mediated induction of the IL-10 promoter in macrophages. J Immunol. 2000;164:1940-51.

122. Liu YW, Tseng HP, Chen LC, Chen BK, Chang WC. Functional cooperation of simian virus 40 promoter factor 1 and CCAAT/enhancer-binding protein beta and delta in lipopolysaccharide-induced gene activation of IL-10 in mouse macrophages. J Immunol. 2003:171(2):821-8.

123. Cao S, Liu J, Song L, Ma X. The protooncogene c-Maf is an essential transcription factor for IL-10 gene expression in macrophages. J Immunol. 2005;174(6):3484-92

124. Liu YW, Chen CC, Tseng HP, Chang WC. Lipopolysaccharide-induced transcriptional activation of interleukin-10 is mediated by MAPK- and NFkappaB-induced CCAAT/enhancer-binding protein delta in mouse macrophages. Cell Signal. 2006;18(9):1492-500.
125. Ananieva O, Darragh J, Johansen C, Carr JM, Mcllrath J, Park JM, Wingate A, Monk CE, Toth R, Santos SG, Iversen L, Arthur JS. The kinases MSK1 and MSK2 act as negative regulators of Toll-like receptor signaling. Nat Immunol. 2008:9(9):1028-36.

126. Iyer SS, Cheng G. Role of Interleukin 10 Transcriptional Regulation in Inflammation and Autoimmune Disease. Crit Rev Immunol. 2012;32(1):23-63

127. Lawrence T. The Nuclear Factor NF-kB Pathway in Inflammation. Cold Spring Harb Perspect Biol. 2009;10(1):1-10.

128. Tomczak MF, Erdman SE, Davidson A, Wang YY, Nambiar PR, Rogers AB, Rickman B, Luchetti D, Fox JG, Horwitz BH. Inhibition of Helicobacter hepaticus-induced colitis by $\mathrm{L}-10$ requires the p50/p105 subunit of NF-KB. J Immunol. 2006;177:7332-9.

129. Cao S, Zhang X, Edwards JP, David MM. NF-kB1 (p50) Homodimers Differentially Regulate Pro- and Anti-inflammatory Cytokines in Macrophages. J Biol Chem. 2006;281(36):26041-50.

130. Duncan SA, Zhong Z, Wen Z, Darnell Jr JE. STAT signaling is active during early mammalian development. Dev Dyn. 1997;208(2):190-8.

131. Johnston PA, Grandis JR. STAT3 signaling: anticancer strategies and challenges. Mol Interv. 2011;11(1):18-26.

132. Stark GR, Kerr IM, Williams BRG, Silverman RH, Schreiber RD. How cells respond to interferons. Annu Rev Biochem. 1998;67:227-64.

133. Yu H, Pardoll D, Jove R. STATs in cancer inflammation and immunity: a leading role for STAT3. Nat Rev Cancer. 2009;9(11):798-809.

134. Staples KJ, Smallie T, Williams LM, Foey A, Burke B, Foxwell BMJ, Heitbrock LZ. IL-10 Induces IL-10 in Primary Human Monocyte-Derived Macrophages via the Transcription Factor Stat3. J Immunol. 2007:178:4779-85.

135. Paul G, Khare V, Gasche C. Inflamed gut mucosa: downstream of interleukin10. Eur J Clin Invest. 2012;42:95-109.

136. Brenner S, Prösch S, Schenke-Layland K, Riese U, Gausmann U, Platzer C. CAMP-induced interleukin-10 promoter activation depends on CCAAT/ enhancer-binding protein expression and monocytic differentiation. J Biol Chem. 2003;278:5597-604.

137. Kinjyo I, Inoue H, Hamano S, Fukuyama S, Yoshimura T, Koga K, et al. Loss ofSOCS3 in Thelper cells resulted in reduced immune responses and hyperpro-duction of interleukin 10 and transforming growth factor-beta 1. J Exp Med. 2006;203:1021-31.

138. Hoentjen F, Sartor RB, Ozaki M, Jobin C. STAT3 regulates NF-kappaB recruit-ment to the $\mathrm{IL}-12 \mathrm{p} 40$ promoter in dendritic cells. Blood. 2005;105:689-96.

139. Liu Y, Wang X, Jiang J, Cao Z, Yang B, Cheng X. Modulation of T cell cytokine production by miR-144 with elevated expression in patients with pulmonary tuberculosis. Mol Immunol. 2011;48:1084-90.

140. Turner ML, Schnorfeil FM, Brocker T. MicroRNAs regulate dendritic cell differentiation and function. J Immunol. 2011;187(8):3911-7.

141. O'Connell RM, Rao DS, Chaudhuri AA, Baltimore D. Physiological and pathological roles for microRNAs in the immune system. Nat Rev Immunol. 2010;10:111-22.

142. Biswas SK, Mantovani A. Macrophage plasticity and interaction with lymphocyte subsets: cancer as a paradigm. Nat Immunol. 2010;11:889-96.

143. Ma S, Liu M, Xu Z, Li Y, Guo H, Ge Y, Liu Y, Zheng D, Shi J. A double feedback loop mediated by microRNA-23a/27a/24-2 regulates $M 1$ versus $M 2$ macrophage polarization and thus regulates cancer progression. Oncotarget. 2016;7(12):13502-19.

144. Feng $M$, Xingguang $L$, Dong $L$, Pin W, Nan L, Liwei L, Xuetao C. MicroRNA466 | Upregulates IL-10 Expression in TLR-Triggered Macrophages by Antagonizing RNA-Binding Protein Tristetraprolin-Mediated IL-10 mRNA Degradation. J Immunol. 2010;184:6053-9.

145. Rossatoa M, Curtaleb G, Tamassiaa N, Castelluccia M, Morib L, Gasperinia S, Mariottia B, Lucab MD, Mirolob M, Cassatellaa MA, Locatib M, Bazzonia F. IL10-induced microRNA-187 negatively regulates TNF- $a, I L-6$, and IL-12p40 production in TLR4-stimulated monocytes. PNAS. 2012;109(45):E3101-3110.

146. Cardwell LN, WeaverB K. IL-10 Inhibits LPS-Induced Expression of miR-147 in Murine Macrophages. Adv Biol Chem. 2014;4:261-73.

147. Liu Y, Chen Q, Song Y, Lai L, Wang J, Yu H, Cao X, Wang Q. MicroRNA-98 negatively regulates $\mathrm{IL}-10$ production and endotoxin tolerance in macrophages after LPS stimulation. FEBS Lett. 2011:585:1963-8.

148. Xie N, Cui H, Banerjee S, Tan Z, Salomao R, Fu M, Abraham E, Thannickal VJ, Liu G. miR-27a Regulates Inflammatory Response of Macrophages by Targeting IL-10. J Immunol. 2014;193:327-34. 
149. Freilich RW, Woodbury ME, Ikezu T. Integrated Expression Profiles of mRNA and miRNA in Polarized Primary Murine Microglia. PLoS ONE. 2013;8(11):79416.

150. Fleetwood AJ, Dinh H, Cook AD, Hertzog PJ, Hamilton JA. GM-CSF- and MCSF-dependent macrophage phenotypes display differential dependence on type I interferon signaling. J Leukoc Biol. 2009;86:411-21.

151. Lawrence T, Natoli G. Transcriptional regulation of macrophage polarization: enabling diversity with identity. Immunology. 2005;11:750-61.

152. Mills CD, Kincaid K, Alt JM, Heilman MJ, Hill AM. M-1/M-2 macrophages and the Th1/Th2 paradigm. J Immunol. 2000;164:6166-73.

153. Ouimet M, Hasini NE, Mahesh GU, Frederick JS, Bhama R, Susan BH, Kaitlyn R, Coen VS, Morgan DF, Katharine C, Katey JR, Gregory RS, Phillip DZ, Edward AF, Png L, Kathryn JM. MicroRNA-33-dependent regulation of macrophage metabolism directs immune cell polarization in atherosclerosis. J Clin Invest. 2015:125(12):4334-48.

154. Su R, Dong L, Zou D, Zhao H, Ren Y, Li F, Yi P, Li L, Zhu Y, Ma Y, Wang J, Wang F, Yu J. microRNA-23a, -27a and -24 synergistically regulate JAK1/ Stat 3 cascade and serve as novel therapeutic targets in human acute erythroid leukemia. Oncogene. 2016;35:6001-14.

155. Li W, Huang H, Su J, Ji X, Zhang X, Zhang Z, Wang H. miR-124 Acts as a Tumor Suppressor in Glioblastoma via the Inhibition of Signal Transducer and Activator of Transcription 3. Mol Neurobiol. 2016 doi: 10.1007/s12035016-9852-z.

156. Hong L, Ya-Wei L, Hai W, Qiang Z, Jun-Jie L, Huang A, Song-Tao Q, Yun-Tao L. MiR-519a functions as a tumor suppressor in glioma by targeting the oncogenic STAT3 pathway. J Neurooncol. 2016;128(1):35-45.

157. Wang X, Qiu W, Zhang G, Xu S, Gao Q, Yang Z. MicroRNA-204 targets JAK2 in breast cancer and induces cell apoptosis through theSTAT3/BCI-2/survivin pathway. Int J Clin Exp Pathol. 2015;8(5):5017-25.

158. Kalechman Y, Gafter U, Weinstein T, Chagnac A, Freidkin I, Tobar A. Inhibition of interleukin-10 by the immunomodulator AS101 reduces mesangial cell proliferation in experimental mesangioproliferative glomerulonephritis: association with dephosphorylation of STAT3. J Biol Chem. 2004;279(24):724-32

159. Pengal RA, Ganesan LP, Wei G, Fang H, Ostrowski MC, Tridandapani S. Lipopolysaccharide-induced production of interleukin-10 is promoted by the serine/threonine kinase Akt. Mol Immunol. 2006:43:1557-64.

160. Sinuani I, Joshua W, llia B, Micha JR, Judit S, Leonid F, Michael A, Zhan A, Benjamin S. The cyclin kinase inhibitor p57kip2 regulates TGF- $\beta$-induced compensatory tubular hypertrophy: effect of the immunomodulator AS101. Nephrol Dial Transplant. 2009;24:2328-38.

161. Myers RR, Sekiguchi Y, Kikuchi S, Scott B, Medicherla S, Protter A, Campana WM. Inhibition of p38 MAP kinase activity enhances axonal regeneration. Exp Neurol. 2003;184:606-14.

162. Xiang D, Yuan Y, Li CXL, Chandra B, Hua C. Niclosamide, an anti-helminthic molecule, downregulates the retroviral oncoprotein Tax and pro-survival Bcl-2 proteins in HTLV-1-transformed T lymphocytes. Biochem Biophys Res Commun. 2015:464(1):221-8.

163. Shou Y, Rui L, Dongkyoo P, Maohua X, Gabriel LS, Ya C, Zhi-Qiang X, Xingming D. Disruption of STAT3 by Niclosamide Reverses Radioresistance of Human Lung Cancer. Mol Cancer Ther. 2014;13(3):606-16.

164. Farrell D, Shaughnessy RG, Britton L, David E, Mac H, Bryan M, Stephen VG. The Identification of Circulating MiRNA in Bovine Serum and Their Potential as Novel Biomarkers of Early Mycobacterium avium subsp paratuberculosis Infection. PLoS ONE. 2015;10(7):1-22.

165. Shaughnessy RG, Farrell D, Riepema K, Bakker D, Stephen V, Gordon SV. Analysis of Biobanked Serum from a Mycobacterium avium subsp paratuberculosis Bovine Infection Model Confirms the Remarkable Stability of Circulating miRNA Profiles and Defines a Bovine Serum miRNA Repertoire. PLoS ONE. 2015;10(12):1-2.

\section{Submit your next manuscript to BioMed Central and we will help you at every step:}

- We accept pre-submission inquiries

- Our selector tool helps you to find the most relevant journal

- We provide round the clock customer support

- Convenient online submission

- Thorough peer review

- Inclusion in PubMed and all major indexing services

- Maximum visibility for your research

Submit your manuscript at www.biomedcentral.com/submit

) Biomed Central 